J. Egypt. Soc. Parasitol. (JESP), 51(1), 2021: 139 - 146

(Online: 2090-2549)

\title{
EVALUATION OF GIARDIA LAMBLIA TREATMENT IN EXPERIMENTALLY
} INFECTED HAMSTERS

\section{By}

SHIMAA MOHAMMED ABDEL AAL ${ }^{1}$, ABDALLAH MICHEL BOGHDADI ${ }^{1}$, NAGLAA FOUAD ABBAS IMAM ${ }^{1}$, IBRAHIM RABIA ALY ${ }^{2}$, And ABEER SAID ABDEL- GHANY AL-ANTABLY ${ }^{1^{*}}$

Department of Medical Parasitology ${ }^{1}$, Faculty of Medicine, Cairo University, and Department of Medical Parasitology ${ }^{2}$, Theodore Bilharz Research Institute, Imbaba, P.O. Box 30, Giza, Egypt ('Correspondence: asalantably@kasralainy.edu.eg, Orchid ID: 0000-0002-8381-7002)

\begin{abstract}
This study evaluated Curcumin Chitosan nanoparticles versus Nitazoxanide on G. lamblia infected hamsters. They were divided into six groups: G1 healthy, G2 infected, G3 infected treated with Nitazoxanide, G4 infected treated with Curcumin, G5 infected treated with Chitosan nanoparticles and G6 infected treated with Curcumin Chitosan nanoparticles. Treatment started 3 weeks post infection. Stool samples were daily collected and examined. The results showed reduction in cysts in Nitazoxanide, Curcumin, Chitosan nanoparticles and Curcumin Chitosan nanoparticles treated groups compared to control.

Key words: Giardiasis - Curcumin - Chitosan - Nano particles - Nitazoxanide.
\end{abstract}

\section{Introduction}

Giardia species are unicellular flagellates that infect the gut of many vertebrates (Thompson and Monis, 2012), by ingestion of cysts either by fecal oral route or indirectly by consumption of contaminated food or water (Gardner and Hill, 2001). Clinical manifestations varied between asymptomatic to severe symptomatic cases (Anuar et al, 2015), which was characterized by watery, sometimes foul-smelling diarrhea alternated with soft, greasy stools, fatigue, stomach cramps and bloating, gas, nausea, and weight loss (Lalle, 2010). Moreover, giardiasis and Helibacter pylori co-infection is common in Egyptian school aged children and modulates gastrointestinal manifestations (El-Badry et al, 2017). The risky groups were children than adults, pregnant women and immune compromised people or without access to safe drinking water (Faubert, 2000).

Diagnosis of Giardia is based on detection of microscopic cyst in stool samples (Soares and Tasca, 2016) or duodenal sampling (Beal et al, 1970) and the update on the evaluation, diagnosis (Leung et al, 2019).

Medications included Metronidazole or Flagyl ${ }^{\circledR}$ (Abdel-Fattah and Nada, 2007), and Tinidazole or Tindamax ${ }^{\circledR}$ both have many side effects, but it can be given in a single dose (Vakkilainen et al, 2020). Also, Nitazoxanide $\left(\right.$ Alinia $\left.^{\circledR}\right)$ in a liquid form, nitazoxanide may be easier for children to swallow. Side effects may include nausea, gas, yellow eyes and brightly colored yellow urine (Matadamas-Martínez et al, 2020).

Chitosan is primarily chitin product widely distributed in nature, mainly as the structural component of the exoskeletons of crustaceans, insects, in marine diatoms \& algae, as well as in some fungal cell walls (Tharanathan and Kittur, 2003). Commercial interest in chitosan and its derivatives rose from the fact that they combine several favorable biological characters, included biodegradability, biocompatibility and non-toxicity that made them valuable materials for therapeutic, biomedical and industrial applications (Raafat and Sahl, 2009). Meanwhile, curcumin have therapeutic properties of antioxidant, anti-inflammatory and remarkable safety for oral ingestion with poor aqueous solubility and rapid metabolism (Bavarsad et al, 2018), effectiveness in colon cancer (Baell and Walters, 2014), and Alzheimer's disease (Brondino et al, 2014) and others,

This study aimed to use curcumin chitosan nanoparticles in treating giardiasis experim- 
entally infected hamsters.

\section{Materials and Methods}

Experimental animals: A total of 54 parasite-free laboratory bred, male hamsters of 7 weeks old \& weighed about 80-120gm were used. They were divided into six groups of nine hamsters each as GI: Healthy neither infected nor treated (negative control), G2: Infected but untreated (positive control), G3: Infected and Nitazoxanide $(100 \mathrm{mg} / \mathrm{kg} / \mathrm{day})$. G4: Infected and Curcumin $(20 \mathrm{mg} / \mathrm{kg} /$ day $)$. G5: Infected and chitosan nanoparticle (100 $\mu \mathrm{g} / \mathrm{kg} /$ day). G6: Infected and Curcumin Chitosan nanoparticle $(100 \mu \mathrm{g} / \mathrm{kg} /$ day $)$. All drugs were given 7 days after ensuring infection.

Parasite: Fresh stool samples positive only for G. lamblia cysts were obtained from diarrheic patients attended Parasitology Department's Diagnostic and Research Unit. Positivity was approved by stained Modified Ziehl-Neelsen smear and formalin-ethyl acetate concentration examinations (Garcia, 2007).

Preparation of infective inoculum: Positive samples were pooled together, emulsified in normal saline, centrifuged at 2000rpm for 10 min. and sediment cysts were counted by hemocytometer. About 1000cysts/milliliter were prepared. All groups except G1 were orally infected with $1 \mathrm{ml}$ cysts by an esophageal tube. Weekly post-infection, hamsters' fecal samples were collected and examined for giardiasis infections (Dyab et al, 2016). After approving giardiasis infection, drugs were given in a single daily dose for seven consecutive days.

Chitosan nanoparticles preparation (Fernandez-Urrusuna et al, 1999): A total of 500 $\mathrm{mg}$ of Chitosan (medium molecular weight and $85 \%$ deacetylate, Sigma, St. Louis, USA) was dissolved in $50 \mathrm{ml}$ of $1 \%$ Acetic acid and stirred at $1000 \mathrm{rpm}$ for $25 \mathrm{~min}$ at room temperature until the solution became clear.

Curcumin loaded nanoparticles (Mofazzal et al, 2015) were prepared by adding chitosan to TPP solution with $500 \mathrm{mg}$ curcumin and chitosan $(3 \mathrm{mg} / \mathrm{ml})$.

Nitazoxanide (Nanazoxid): 500mg tablets were smashed, weighed, dissolved in distilled water and given to hamsters using esophageal tube in a dose of $100 \mathrm{mg} / \mathrm{kg}$ bodyweight for 7 days (Abd El-Aziz et al, 2014).

Curcumin longa: Curcumin powder was suspended in water 1:10 and given orally in a single dose of $20 \mathrm{mg} / \mathrm{kg} /$ day dose for $7 \mathrm{da}$ ys (Bharti et al, 2003).

Treatment efficacy was done by cysts in feces (absent, or viability \& count), by using $0.1 \%$ eosin vital stain $15 \mathrm{~min}$. after exposure, cysts without absorbed dye were potentially viable (Fathy, 2011).

Chemical examinations: Seven days posttreatment the ALT, AST, serum urea, serum creatinine, WBCs, RBCs, and platelet count were measured (Bartels et al, 1972).

Ethical approval: The work was approved by the Institutional Animal Care and Use Committee (IACUC), Cairo University.

Statistical analyses: Data were collected, tabulated and analyzed by using SPSS software version 20. Percentages were used to express the rates. Chi square test compared the differences among groups of variables. $\mathrm{P}$-value at $<0.05$ was significance.

\section{Results}

The results were given in tables $(1 \& 20$ and figure (1).

Table 1: Comparison between mean cysts count/gm faeces (Reduction \%) at different days P.T. within groups

\begin{tabular}{|l|c|c|c|c|c|c|c|}
\hline Groups & $\begin{array}{c}\text { Cysts/gm on } \\
1^{\text {st }} \text { day }\end{array}$ & $\begin{array}{c}\text { Cysts/gm on } \\
2^{\text {nd }} \text { day }\end{array}$ & $\begin{array}{c}\text { Cysts/gm on } \\
3^{\text {rd }} \text { day }\end{array}$ & $\begin{array}{c}\text { Cysts/gm on } \\
4^{\text {th }} \text { day }\end{array}$ & $\begin{array}{c}\text { Cysts/gm on } \\
5^{\text {th }} \text { day }\end{array}$ & $\begin{array}{c}\text { Cysts/gm on } \\
6^{\text {th }} \text { day }\end{array}$ & $\begin{array}{c}\text { Cysts/gm on } \\
7^{\text {th }} \text { day }\end{array}$ \\
\hline G2 & $10500 \pm 386$ & $11200 \pm 589.9$ & $12033.3 \pm 612.1$ & $11566.7 \pm 621.8$ & $12816.7 \pm 865.8$ & $12666.7 \pm 875.6$ & $12333.3 \pm 843$ \\
\hline \multirow{2}{*}{ G3 } & $4993.3 \pm 72.6$ & $4833.3 \pm 196.6$ & $4450 \pm 225.8$ & $3133.3 \pm 709$ & $2083.3 \pm 649.4$ & $1266.7 \pm 332.7$ & $650 \pm 137.8$ \\
& $(52.4 \%)$ & $(56.8 \%)$ & $(63 \%)$ & $(72.9 \%)$ & $(83.7 \%)$ & $(90 \%)$ & $(94.7 \%)$ \\
\hline \multirow{2}{*}{ G4 } & $9916.7 \pm 285.8$ & $10266.7 \pm 420.3$ & $11141.7 \pm 241.7$ & $10333.3 \pm 493.6$ & $11405 \pm 752.4$ & $11300 \pm 608.3$ & $11000 \pm 380.8$ \\
& $(5.6 \%)$ & $(8.3 \%)$ & $(7.4 \%)$ & $(10.7 \%)$ & $(11 \%)$ & $(10.8 \%)$ & $(10.8 \%)$ \\
\hline \multirow{2}{*}{ G5 } & $8266.7 \pm 605.5$ & $7963.3 \pm 606.7$ & $7165.8 \pm 249.6$ & $6558.3 \pm 466$ & $6116.7 \pm 449.1$ & $5838.3 \pm 316.8$ & $5641.78 \pm 305.6$ \\
& $(21.3 \%)$ & $(28.9 \%)$ & $(40.5 \%)$ & $(43 \%)$ & $(52.2 \%)$ & $(53.9 \%)$ & $(54.3 \%)$ \\
\hline \multirow{2}{*}{ G6 } & $8416.7 \pm 803.5$ & $8020 \pm 1023.1$ & $7817.3 \pm 1037.7$ & $7538.3 \pm 1026.9$ & $8533.3 \pm 1080.1$ & $8436.7 \pm 1064.2$ & $8301.7 \pm 1043.4$ \\
& $(19.8 \%)$ & $(28.4 \%)$ & $(35 \%)$ & $(34.8 \%)$ & $(33.4 \%)$ & $(33.4 \%)$ & $(32.7 \%)$ \\
\hline
\end{tabular}


After 7 days, cysts in G3, G4 \& G6 showed significant difference $(\mathrm{p}<0.001)$ compared to $\mathrm{G} 2$, but $\mathrm{G} 4$ not significant $(\mathrm{P}>0.05)$. Compared to G3, cysts in G4, G5 \& G6 showed a high significant difference $(\mathrm{P}<0.001)$. Compared with G4 \& G5, cysts in G3, G4 \&
G6 showed a high significant difference (P $<0.001)$, but $\mathrm{G} 2$ not significant $(\mathrm{P}>0.05)$. Compared with G5 cysts in G2, G3 \& G4 showed a high significance $(\mathrm{p}<0.001)$, but G6 not significant $(\mathrm{P}>0.05)$. Viability was in G2, G3, G4, G5, \& G6 (Tab. 2).

Table 2: Comparison between groups as to cysts' viability and reduction.
\begin{tabular}{|l|l|l|}
\hline Group & Viability $7^{\text {th }}$ day & Reduction \\
\hline G2 (positive control) & $95.7 \pm 2.7$ & \\
\hline G3 (NTZ) & $29.5 \pm 3.3$ & $69.2 \%$ \\
\hline G4 (Curcumin) & $93.8 \pm 1.6$ & $1.9 \%$ \\
\hline G5 (Chitosan nanoparticles) & $40 \pm 9.5)$ & $58.2 \%$ \\
\hline G6 (Curcumin Chitosan nanoparticles) & $62.5 \pm 8.2$ & $34.7 \%$ \\
\hline
\end{tabular}

Viability was in all infected treated G3, G5 \& G6 with high significant difference ( $p$ $<0.001$ ) compared to $\mathrm{G} 2$, but G4 not significant $(\mathrm{P}>0.05)$ compared to $\mathrm{G} 2$. Viability in G2, G4, \& G6 showed a high significant difference $(p<0.001)$, but G5 not significant ( $p>0.05$ ) compared to G3. All blood parameters except WBCS showed no significant difference in all groups ( $\mathrm{p}>0.05)$ compared to $\mathrm{G} 1$, but WBCS in $\mathrm{G} 2$, G3, G4, G5 \& G6 showed a high significant difference (P $<0.001$ compared to G1. All chemical blood parameters showed no significant difference $(\mathrm{P}>0.05)$ in all except $\mathrm{G} 4$ compared to $\mathrm{G} 1$, and in G4 showed a high significant difference $(\mathrm{P}<0.001$ compared to $\mathrm{G} 1$.

\section{Discussion}

Endemic giardiasis was reported from many Egyptian Governorates among different sectors. El-Shazly et al. (2004) identified the genotypes of the Egyptian Giardia lamblia. Hassanein et al. (2017) in Alexandria reported $G$. lamblia and $H$. pylori infections among mentally challenged individuals in rehabilitation center. Naguib et al. (2018) identified age pattern of Cryptosporidium species and Giardia duodenalis in Egyptian dairy calves. Hamdy et al. (2019) in BeniSuef Governorate assessed Giardia and Cryptosporidium assemblages/species in potable tap water. Abd El-Latif et al. (2020) in Alexandria Governorate reported that the presence of the same Giardia sub-assemblage in diarrheic children and in raw water samples shown by molecular evidence the potential for waterborne dissemination of Giardia in
Egypt. Mohamed et al. (2020) in Sharkia Governorate reported giardiasis among the symptomatic children.

Many drugs were used as anti-giardiasis, but with adverse activities (Fallah et al, 2007), due to the development of drugs resistance (Harris et al, 2000; Vivancos et al, 2018). Many studies investigated the invitro antigiardial properties of other commonly used medicinal plants (Anquez-Traxler, 2011; Sadjadi et al, 2006; Saffarharandi et al, 2006; Shahabi et al, 2008).

Carter et al. (2018) in the United Kingdom stated that with the nitroimidazoles growing number of refractory, clinicians were increasingly falling back on second-line and less well-known drugs to treat giardiasis. Dafni and Böck (2019) stated that all the Biblical Medicinal Plants were known as such in Ancient Egypt and/or Mesopotamia also. Examination of the list showed that all these plants were in continuous medicinal use in the Middle East down the generations, as well as being used in the Holy Land today. Precisely in King Solomon's words, "That which has been is what will be, that which is done is what will be done. And there is nothing new under the sun" (Ecclesiastes 1:9).

In the present work, the four drugs used, showed different degrees in decreasing number of $G$. lamblia cysts and viability. But, none of them gave a complete eradication of cysts. This agreed with Nabarro et al. (2018) who reported that none of the anti-giardial treatments gave $100 \%$ parasitological cure rates, particularly failure of 
treatment occurred in patients with hypoganmaglobulinaemia or human immunodeficiency virus (HIV), or be due to nitroimidazole-resistant organisms.

In the present study NTZ proved to be the most effective drug against giardiasis as it gave $(94.7 \%)$ reduction in cysts number and $(69.2 \%)$ in cysts viability compared to negative control with highly significant difference. This agreed with Müller et al. (2006), who found that NTZ induced (95\%) of the Giardia trophozoites, and Navarrete-Vázquez et al. (2015) in-vitro found that NTZ gave marked efficacy against $G$. intestinalis. Also, Abdel-Hafeez et al. (2016) who evaluated Zingiber officinale extract compared to NTZ in (PBS) as controls gave (92.93\%) decrease in giardiasis.

Moreover, clinically Romero Cabello et al. (1997) in Mexico and Abaza et al. (1998) in Egypt evaluated NTZ in treating giardiasis infections, reported cure rate of $71 \%$ \& $94 \%$ respectively.

In the present study, curcumin was the least effective drug against Giardia cysts, with $10.8 \%$ reduction in number and $1.9 \%$ reduction in viability. Chan et al. (2005) reported that curcumin gave non-significant reduction in cysts number due to its anti-inflammatory activity, which exacerbation infection. Also, Said et al. (2012) reported a low reduction rate (13.1\%) of G. lamblia cysts. But, Dyab et al. (2016) in vitro evaluated the anti-giardiasis efficacy of dichloromethane extracts of $C$. longa versus MTZ, and found that the dichloromethane extract gave a lethal effect up to $(85 \%)$ on Giardia cysts. However, the lethat effect varied from one study to another as to the solvent used and extraction system of medicinal plants, part used and their essential oils (Rios and Recio, 2005; Amaral et al, 2006). Pérez-Arriaga et al. (2006) reported that curcumin caused cytotoxic effect, which inhibited Giardia growth, adherence capacity, and motility.

With chitosan nanoparticles, reduction in number of cysts and viability were $52.3 \%$, \& $58.2 \%$ respectively (Li et al, 2013). Besides, chitosan modulated the immune response by increasing cellular and humoral immunity (Choi et al, 2016). The chitosan nanoparticles, with its biological properties, minimized toxicity in crossing the body physiological barrier access to specific target tissues (Jahangiri and Barghi, 2018).

This agreed with Yarahmadi et al. (2016) who reported that chitosan affected giardiasis cysts viability causing complete mortality. Also, Said et al. (2012) reported that the anti-parasitic activity of Chitosan and Chitosan nanoparticles, which reduced cysts' number $(44.2 \%, \& 68.2 \%)$ respectively.

The present data disagreed with Chabra et al. (2019) who in vitro found that the mortality rate of Giardia cysts treated with fungal chitosan, and chitosan nanoparticles was $78 \& 87 \%$, respectively. The chitosan have the potential development advantage of the anti-giardiasis (Chabra et al, 2019).

In the present, curcumin chitosan nanoparticles reduced the cysts number and viability $(32.7 \%$, \& $34.7 \%)$ respectively. The significant reduction in cysts number by curcumin chitosan nanoparticles may be due to the fact that it increased the bioavailability to target tissues. Said et al. (2012) in experimentally giardiasis infected rats found that combination curcumin and chitosan nanoparticles caused $(81.3 \%)$ reduction in the G. lamblia cysts. Besides, chitosan nanoparticles successfully treated Leishmania infantum (Kayser, 2001, Plasmodium falciparum (Föger et al, 2006), and Cryptosporidium parvum (Pujals et al, 2008). Akhtar et al. (2012) found that curcumin chitosan nanoparticles developed activity against Plasmodium yoelii.

In the present study, there was a significant increase in the leukocyte counts in all hamsters groups. This agreed with Al-Haboobi et al. (2013) who found increase in WBCs in children infected with different intestinal protozoa, especially among children infected with active giardiasis.

In the present study, there was significant increase in liver enzymes, urea and creatinine. This agreed with Dundar and Yilmazlar 
(2015) who reported hepatotoxic and hepato-renal syndrome due to natural bi-product like Curcumin. But, Osawa (2007), Wang et al. (2012) and Trujillo et al. (2013) reported that Curcumin was protective to the liver and the kidney especially renal injury.

\section{Conclusion}

The outcome data showed that NTZ gave the highest reduction rate. Chitosan nanoparticles were better than curcumin chitosan nanoparticles in reduction of cysts count and viability. Curcumin was the least one, and increased liver and kidney functions. Chitosan nanoparticle is a promising safe and nontoxic anti-Giardia.

Conflict of Interest: The authors declare that neither have interests or received fund.

Authors' contributions: All authors contributed to the study concept and design, material preparation, data collection, analysis, and discussion, and final approval by Abdel Aal, SM, Boghdadi, AM, Imam, NFA, Aly, IR, and Al-Antably, ASA, The draft manuscript was written by Abdel Aal, SM, Imam, NFA, and Al-Antably, ASA.

\section{References}

Abd El-Latif, NF, El-Taweel, HA, Gaballah, A, Salem, AI, Abd El-Malek, AHM, 2020: Molecular characterization of Giardia intestinalis detected in humans and water samples in Egypt. Acta Parasitol. 65, 2:482-9

Abaza, H, El-Zayadi, A, Kabil, SM, Rizk, H, 1998: Nitazoxanide in the treatment of patients with intestinal protozoan and helminthic infections: a report on 546 patients in Egypt. Curr. Ther. Res. 59:116-21.

Abd El-Aziz, GS, El-Fark, MO, Hassan, SM, Badawoud, MH, 2014: Effects of prolonged oral intake of mono sodium glutamate (MSG) on body weight and its correlation to stomach histopathological changes in male rats. Thai. J. Vet. Med. 44, 2:201-8.

Abdel-Fattah, NS, Nada, OH, 2007: Effect of propolis versus metronidazole and their combined use in treatment of acute experimental giardiasis. J. Egypt. Soc. Parasitol. 37, 2:S691-710

Abdel-Hafeez, EH, Ahmad, AK, Kamal, AM, Belal, US, El-Saghier, NM, 2016: Anti-Giardia lamblia activity of ginger (Zingiber officinale) extract in an improved modified axenic culture.
P.U.J. 9:7-12.

Akhtar, F, Rizvi, MM, Kar, SK, 2012: Oral delivery of Curcumin bound to Chitosan nanoparticles cured Plasmodium yoelii infected mice. Biotechnol. Adv. 30, 1: 310-20.

Al-Haboobi, ZA, Jasim, AKA, Al-Quraishi, MA, 2013: The pattern of leucocytes parameters and C-reactive protein findings of G. lamblia and E. histolytica intestinal infections in children. Inter. J. Rec. Biotech. 1:5-14.

Amaral, FMM, Ribeiro, MNS, Barbosa, JM, Reis, AS, Nascimento, FRF, et al, 2006: Plants and chemical constituents with giardicidal activity. Rev. Bras. Farmacogn. 16: 696-720.

Anquez-Traxler, C, 2011: The legal and regulatory framework of herbal medicinal products in the European Union: A focus on the traditional herbal medicine's category. J. Drug Inf. 45:1523.

Anuar, TS, Moktar, N, Salleh, FM, Al-Mekhlafi, HM, 2015: Human giardiasis in Malaysia: Correlation between the presence of clinical manifestation and Giardia intestinalis assemblage. Southeast Asian J. Trop. Med. Pub. Hlth. 46, 5: 835-43.

Baell, J, Walters MA, 2014: Chemistry: Chemical con artists foil drug discovery. Nature 513: 481-3.

Brondino, N, Boldrini, A, Cuccomarino, A, Lanati, N, Barale, F, et al, 2014: Curcumin as a therapeutic agent in dementia: A mini systematic review of human studies. Sci. World J. 2014, 174282.10.1155/2014/174282

Bartels, H, Bohmer, M, Heierli, C, 1972: Serum creatinine determination without protein precipitation. Clin. Chim. Acta 37:193-7.

Bavarsad, K, Barreto, GE, Hadjzadeh, MA, Sahebkar, A, 2018: Protective effects of Curcumin against ischemia-reperfusion injury in the nervous system. Mol. Neurobiol. 56:1391-404.

Beal, CB, Viens, P, Grant, RG, Hughes, JM, 1970: A new technique for sampling duodenal contents. Am. J. Trop. Med. Hyg. 19:349-52.

Bharti, AC, Donato, N, Aggarwal, BB, 2003: Curcumin (diferuloylmethane) inhibits constitutive and IL-6- inducible STAT3 phosphorylation in human multiple myeloma cells. J. Immunol. 171, 7:3863-71.

Carter, ER, Nabarro, LE, Hedely, L, Chiodini, PL, 2018: Nitroimidazole-refractory giardiasis: A growing problem requiring rational solutions. Clin. Microbiol. Infect. 24, 1:37-42.

Carter, ER, Nabarro, LE, Hedley, L, Chiodi- 
ni, PL, 2018: Nitroimidazole-refractory giardiasis: A growing problem requiring rational solutions. Clin. Microbiol. Infect. 24, 1: 37-42

Chabra, A, Esboei, BR, Habibi, E, Monadi, T, Azadbakht, M, et al, 2019: Effects of some natural products from fungal and herbal sources on Giardia lamblia in vivo. Parasitol. 146, 9:118898.

Chan, MM, Adapala, NS, Fong, D, 2005: Curcumin overcomes the inhibitory effect of nitric oxide on Leishmania. Parasitol. Res. 96, 1:4956.

Choi, B, Jo, DH, Anower, AKMM, Islam, SM S, Sohn, S, 2016: Chitosan as an immunomodulating adjuvant on T-cells and antigen-presenting cells in herpes simplex virus type 1. J. Infect. Mediat. Inflamm. 1:1-12.

Chuah, LH, Billa, N, Roberts, CJ, Burley, JC, Manickam, S, 2011: Curcumin-containing chitosan nanoparticles as a potential muco-adhesive delivery system to the colon. Pharm. Dev. Technol. 10:1-9.

Dafni, A, Böck, B, 2019: Medicinal plants of the Bible-revisited. Ethnobiol. Ethnomed. 15, 1: 57. doi: 10.1186/s13002-019-0338-8.

Dundar, HZ, Yilmazlar, T, 2015: Management of hepato-renal syndrome. World J. Nephrol. 4: 277-86.

Dyab, AK, Yones, DA, Ibraheim, ZZ, Hassan, TM, 2016: Anti giardial therapeutic potential of dichloromethane extracts of Zingiber officinale and Curcuma longa in vitro and in vivo. Parasitol. Res. 115, 7:2637-45.

El-Badry, AA, Ghieth, MA, Ahmed, DA, Ismail, MAM, 2017: Giardia intestinalis and Helicobacter pylori co-infection: Estimated risks and predictive factors in Egypt. J. Egypt. Soc. Parasitol. 47, 1:19-24.

El-Shazly, AM, Mowafy, N, Soliman, M, ElBendary, M, Morsy, AT, et al, 2004: Egyptian genotyping of Giardia lamblia. J. Egypt. Soc. Parasitol. 34, 1:265-80.

Eweis, M, Elkholy, SS, Elsabee, MZ, 2006: Antifungal efficacy of Chitosan and its thiourea derivatives upon the growth of some sugar-beet pathogens. Int. J. Biol. Macromo. 38:1-8.

Fallah, M, Rabiee, S, Moshtaghi, AA, 2007: Comparison between efficacies of a single dose of Tinidazole with a 7 days standard dose course of Metronidazole in giardiasis. Pakistan. J. Med. Sci. 23:43-6.

Fathy, FM, 2011: Effect of Mirazid (Commiphora molmol) on experimental giardiasis. J. Egy- pt. Soc. Parasitol. 41, 1:155-77.

Faubert, G, 2000: Immune response to Giardia duodenalis. Clin Microbiol Rev. 13, 1:35-54.

Fernandez-Urrusuna, R, Romani, D, Calvo, P, Vila-Jato, JL, Alonso, MJ, 1999: Development of a freeze-dried formulation of insulin-loaded chitosan nanoparticles intended for nasal administration. S. T. P. Pharma. Sci. 5: 429-36.

Föger, F, Noonpakdee, W, Loretz, B, Joojuntr, S, Salvenmoser, W, et al, 2006: Inhibition of malarial topoisomerase II in Plasmodium falciparum by antisense nanoparticles. Int. J. Pharm. 319:139-46.

Garcia, LS, 2007: Diagnostic Medical Parasito$\operatorname{logy}, 5^{\text {th }}$ edition. ASM Press

Gardner, TB, Hill, DR, 2001: Treatment of giardiasis. Clin. Microbiol. Rev.14:114-28.

Hamdy, D, El-Badry, A, Abd El Wahab, W, 2019: Assessment of Giardia and Cryptosporidium assemblages/species and their viability in po table tap water in Beni-Suef, Egypt using nested PCR/RFLP and staining. Iran. J. Parasitol. 14, 3:368-78.

Harris, JC, Plummer, S, Turner, MP, Lloyd, D, 2000: The microaerophilic flagellate Giardia intestinalis: Allium sativum (garlic) is an effective anti-giardial. Microbiol. 1, 46: 3119-27.

Hassanein, FI, Shehata, AI, Abdul-Ghani, R, 2017: G. lamblia and $H$. pylori infections among mentally challenged individuals in rehabilitation centers in Alexandria, Egypt. J. Infect. Dev. Ctries. 11, 7:577-82

Jahangiri, A, Barghi, L, 2018: Polymeric nanoparticles: review of synthesis methods and applications in drug delivery. J.A.C.P.M. 1:3847.

Kayser, O, 2001: A new approach for targeting to Cryptosporidium parvum using mucoadhesive nanosuspensions. Res. Appl. 214:83-5.

Lalle, M, 2010: Giardiasis in the post genomic era: Treatment, drug resistance and novel therapeutic perspectives. Infect. Disord. Drug Targ. 10:283-94.

Leung, AKC, Leung, AAM, Wong, AHC, Sergi, CM, Kam, JKM, 2019: Giardiasis: An overview recent pat. Inflamm. Aller. Drug Discov. 13, 2:134-43

Li, X, Min, M, du, N, Gu, Y, Hode, T, et al, 2013: Chitin, Chitosan, and glycated Chitosan regulate immune responses: Novel adjuvants for cancer vaccine. Clin. Dev. Immunol. 387023. doi:10.1155/2013/387023.

Matadamas-Martínez, F, Torres, B, Castillo, 
R, Campos, AH, Barrera-Valdes, ML, 2020: Characterization of the in-vitro activity of a Nitazoxanide-N-methyl-1H-benzimidazole, hybrid molecule against albendazole and nitazoxanide susceptible and resistant strains of Giardia intestinalis and its' in vivo giardicidal activity. Mem. Inst. Oswaldo Cruz Feb 7;115:e190348 doi: 10.1590/0074-02760190348.

Mofazzal, MA, Rajayi, HA, Musawi, S, Pirestani, M, Ramandi, FM, et al, 2015: Evaluation of antibacterial effect of Curcumin loaded Chitosan nanoparticles. J. Fasa. Univ. Med Sci. 5:13441.

Mohamed, AMA, Bayoumy, AM, Abo-Hashim, AH, Ibrahim, AA, El-Badry, AA, 2020: Giardiasis in symptomatic children from Sharkia, Egypt: genetic assemblages and associated risk factors. J. Parasit. Dis. 44, 4:719-24.

Müller, J, Rühle, G, Müller, N, Rossignol, JF, Hemphill, A, 2006: In vitro effects of thiazolides on Giardia lamblia WB clone C6 cultured axenically and in co-culture with Caco 2 cells. Antimicrob. Agents Chemother. 50:162-70.

Nabarro, LE, Lever, RA, Armstrong, M, Chiodini, PL, 2015: Increased incidence of nitroimidazole-refractory giardiasis at the Hospital for Tropical Diseases, London: 2008-2013. Clin. Microbiol. Infect. 21,8:791-6.

Naguib, D, El-Gohary, AH, Mohamed, AA, Roellig, DM, Arafat, N, Xiao, L, 2018: Age patterns of Cryptosporidium species and Giardia duodenalis in dairy calves in Egypt. Parasitol. Int. 67, 6:736-41.

Navarrete-Vázquez, G, Chávez-Silva, F, Lozano, B, Estrada, S, Hidalgo, S, et al, 2015: A Facultad synthesis of nitro(benzo) thiazoleacetamides and in vitro antiprotozoal effect against amitochondriate parasites Giardia intestinalis \& Trichomonas vaginalis. Bioorg. Med. Chem. 23: 2204-6.

Nose, M, Koide, T, Ogihara, Y, Yabu, Y, Ohta, NM, 1998: Trypanocidal effects of Curcumin in vitro. Biol. Pharm. Bull. 21: 643-5.

Osawa, T, 2007: Nephro-protective and hepatoprotective effects of curcuminoids. Adv. Exp. Med. Biol. 595:407-23.

Pérez-Arriaga, L, Mendoza, ML, Cortés-Zárate, R, Corona Rivera, A, Bobadilla-Morales, L, et al, 2006: Cytotoxic effect of Curcumin on Giardia lamblia trophozoites. Acta Trop. 98: 152-61.

Pujals, G, Sune-Negre, JM, Pérez, P, García, E, Portus, M, et al, 2008: In vitro evaluation of the effectiveness and cytotoxicity of meglumine antimoniate microspheres produced by spray $\mathrm{dr}$ ying against Leishmania infantum. Parasitol. Res. 102:1243-7.

Raafat, D, Sahl, HG, 2009: Chitosan and its antimicrobial potential, a critical literature survey. Microb. Biotechnol. 2, 2:186-201.

Rios, JL, Recio, MC, 2005: Medicinal plants and antimicrobial activity. J. Ethno. Pharmacol. 100: \80-4.

Romero Cabello, R, Guerroro, LR, Garcia, $M$ R, Cruz, A, 1997: Nitazoxanide for the treatment of intestinal protozoan and helminthic infections in Mexico. Trans. R. Soc. Trop. Med. Hyg. 91:701-3.

Sadjadi, SM, Rostami, J, Azadbakht, M, 2006: Giardiacidal activity of lemon juice, vinif$e r$ and vinegar on Giardia intestinalis cysts. Southeast. Asi. J. Trop. Med. Pub. Hlth. 37:24-7.

Saffarharandi, MM, Dalimi, AH, Ghaffari, F, 2006: In vitro and in vivo effects of garlic (Allium sativum) extract on Giardia lamblia and Giardia muris. Hakim Res. J. 3:58-64.

Said, DE, EI Samad, LM, Gohar, YM, 2012: Validity of silver, chitosan and curcumin nanoparticles as anti-Giardia agents. Parasitol. Res. 111, 2:545-54.

Shahabi, S, Ayazi Roozbehani, F, Kamalinejad, M, Abadi, A, 2008: Antigiardial activity of Carum copticum on Giardia lamblia cysts in vitro. J. Shahid Beheshti Med. Sci. Hlth. 32:303-7.

Silva, SH, Da Silva-Filho, AA, Rodrigues, V, 2009: In vitro schistosomicidal activity of Curcumin against Schistosoma mansoni adult worms. Parasitol. Res. 104:1197-201.

Soares, R, Tasca, T, 2016: Giardiasis: An update review on sensitivity and specificity of methods for laboratorial diagnosis. J. Microbiol. Meth. 129:98-102.

Tharanathan, RN, Kittur, FS, 2003: Chitin-the undisputed biomolecule of great potential. Crit. Rev. Food Sci. Nutr. 43, 1:61-87.

Thompson, RCA, Monis, PT, 2012: Giardiafrom genome to proteome. Adv. Parasitol.78:5795.

Trujillo, J, Chirino, YI, Molina-Jijón, E, Romero, AC, Tapia, E, et al, 2013: Reno protective effect of the antioxidant Curcumin. Rec. Fnd. Redox Biol. 1:448-56.

Vakkilainen, S, Nieminen, T, Björkbacka, S, Saavalainen, T, Salo, E, 2020: Treatment of giardiasis in children: Randomized trial of rectal metronidazole versus oral tinidazole. J. Infect. 
81, 5:816-46.

Vivancos, V, González-Alvarez, I, Bermejo, M, Gonzalez, M, 2018: Giardiasis: Characteristics, pathogenesis and new insights about treatment. Curr. Top. Med. Chem. 18, 15:1287-303.

Wang, ME, Chen, YC, Chen, IS, Hsieh, SC, Chen, SS, et al, 2012: Curcumin protects against thioacetamide-induced hepatic fibrosis by attenuating the inflammatory response and inducing apoptosis of damaged hepatocytes. J. Nutr.
Biochem. 23:1352-66.

William, S, Ramzy, F, 2008: Testing two antimalarial drugs on Giardia lamblia in experimentally infected hamsters. Res. J. Med. Sci. 4, 1:16.

Yarahmadi, M, Fakhar, M, Ebrahimzadeh, MA, Chabra, A, Rahimiesboei, B, 2016: The anti-giardial effectiveness of fungal and commercial Chitosan against Giardia intestinalis cysts in vitro. J. Parasit. Dis. 40:75-80.

Fig. 1: Mean cysts count in infected groups over 7days P.T.

Explanation of figures

Fig. 2: Giardia lamblia cysts in fresh stool sample.
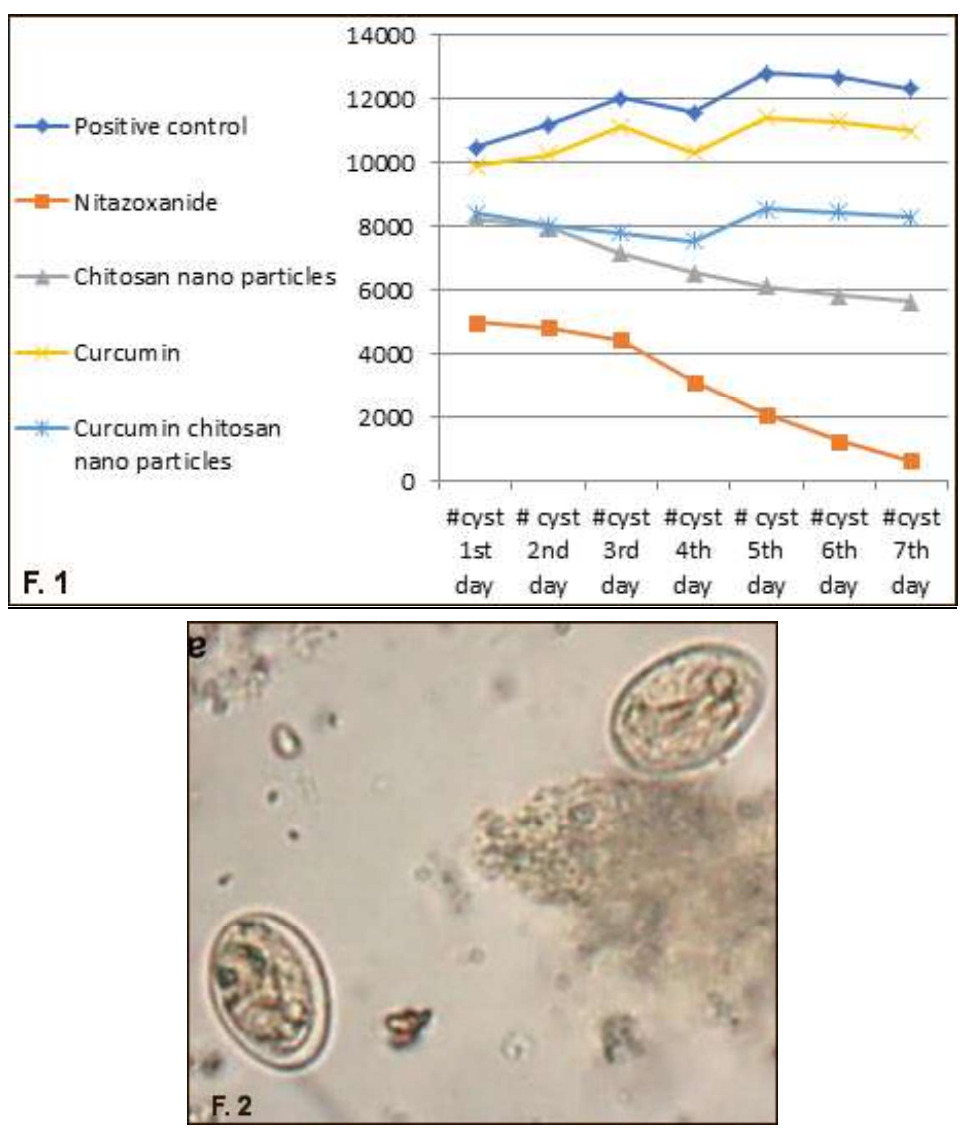